\title{
MEWUJUDKAN MASYARAKAT QUR'ANI DI DESA KALABBIRANG MELALUI PROGRAM KKN STIBA MAKASSAR
}

\author{
Sartini Lambajo \\ Sekolah Tinggil Ilmu Islam dan Bahasa Arab (STIBA) Makassar \\ sartini@stiba.ac.id \\ Akhmad Hanafi Dain Yunta \\ Sekolah Tinggil Ilmu Islam dan Bahasa Arab (STIBA) Makassar \\ ahmadhanafi@stiba.ac.id
}

\begin{abstract}
Keywords : ABSTRACT

Kalabbirang Vilage, Student A community service program is one form of the tri dharma of of KKN, Quranic higher education that can be conducted through Student Community, STIBA Community Service (KKN) activities. One village that is the location for the performance of the STIBA Makassar KKN is

Makassar Kalabbirang Village, which is located in Bantimurung District, Maros Regency, South Sulawesi. This article aims to describe the community service process managed by STIBA Makassar students in Kalabbirang Village. The program activities conducted were 1) blessful Friday; 2) Fiqh ta'lim for Muslim women; 3) Teaching TPA; 4) Dirosa program; 5) Tahsin program; 6) Tarbiyah Islamiyah; 7) Halaqah lughawiyah; 8) ta'lim for youth; 9) ta'lim for youth; 10) Tadabur of nature; 11) Handicraft training; 12) Training on burial ritual; 13) Festival of religious children. The results of the community service program contributed considerably to the formation of the Quranic community for the people in Kalabbirang Village.
\end{abstract}

Kata kunci :

Desa Kalabbirang, KKN

Mahasiswa, Masyarakat

Qur'ani, STIBA Makassar,

\section{ABSTRAK}

Program pengabdian masyarakat salah satunya dilakukan melalui kegiatan KKN Mahasiswa. Salah satu Desa yang menjadi daerah pelaksanaan KKN STIBA Makassar adalah Desa Kalabbirang, yang terletak di Kecamatan Bantimurung, Kabupaten Maros, Sulawesi Selatan. Artikel ini bertujuan untuk memberikan deskripsi proses pengabdian masyarakat yang dilakukan oleh mahasiswi STIBA Makassar di Desa Kalabbirang. Adapun program kegiatan yang dilakukan adalah 1) Jum'at berkah; 2) Taklim fikih muslimah; 3) Pembinaan TPA; 4) Program dirosa; 5) Program tahsin; 6) Tarbiyah islamiyah; 7) Halaqoh luhgawiyah; 8) Taklim remaja; 9) Taklim remaja; 10) Tadabbur alam; 11) Pelatihan kerajinan tangan; 12) Pelatihan penyelenggaraan jenazah; 13) Festival anak saleh. Hasil program pengabdian masyarakat memberikan kontribusi yang baik dalam pembentukan masyarakat Q'ur'ani bagi masyarakat di Desa Kalabbirang. 


\section{PENDAHULUAN}

\section{A. Profil Kelurahan Kalabbirang, Kecamatan Bantimurung, Kabupaten Maros}

\section{Geografis}

Kelurahan Kalabbirang merupakan salah satu kelurahan yang berada di wilayah Kecamatan Bantimurung, Kabupaten Maros, Provinsi Sulawesi Selatan. Kelurahan Kalabbirang berstatus sebagai kelurahan defenitif dan tergolong pula sebagai kelurahan swasembada. Kelurahan Kalabbirang memiliki luas wilayah $7,25 \mathrm{~km}^{2}$ dan jumlah penduduk sebanyak 4.365 jiwa dengan tingkat kepadatan penduduk sebanyak 602,07 jiwa/ $\mathrm{km}^{2}$ pada tahun $2017 .{ }^{1}$

Secara administrasi, Kelurahan Kalabbirang terbagi ke dalam 2 lingkungan yaitu Lingkungan Pakalu (terdapat $11 \mathrm{RT}$ ) dan Lingkungan Tompobalang (terdapat 4 RT).Adapun posisi geografis berbatasan dengan wilayah berikut: 1) Sebelah utara berbatasan dengan Kelurahan Leang-leang; 2) Sebelah timur berbatasan dengan Kecamatan Camba; 3) Sebelah selatan berbatasan dengan Jenetaesa; 4) Sebelah barat berbatasan dengan Desa Minasa Baji.

\section{Demografi}

Kelurahan Kalabbirang memiliki jumlah penduduk dengan rincian laki-laki sebanyak1927 orang dan perempuan sebanyak2059 orang. Jumlah total (laki-laki dan perempuan) sebanyak 3986 orang dengan jumlah kepala keluarga sebanyak $984 \mathrm{KK}$. Kelurahan Kabbirang memiliki dua RW yaitu Pakalu dan Tompobalang. Lingkungan Pakalu terdapat 11 RT dan Lingkungan Tompobalang 4 RT. Jumlah rumah di Kelurahan Kalabbirang adalah 1087 rumah.

\section{Topografi}

Sebagian besar wilayah adalah dataran rendah dan gunung. Ketinggian rata-rata 500 mdpl. Keadaan iklim tergolong kategori beriklim tropis, mempunyai bulan basah 79 bulan yang umumnya jatuh pada bulan november sampai bulan mei, sedangkan bulan kering 2-3 bulan dan biasanya jatuh pada bulan juni sampai bulan oktober dengan temperatur 20 sampai 30 derajat celcius. Adapun jenis tanah di kelurahan Kalabbirang termasuk jenis tanah aluvial, dengan $\mathrm{PH}=5,5$ sampai 7 dan lahan sawah 5 sampai 6.

\section{B. Potensi Lokal Kelurahan Kalabbirang, Kecamatan Bantimurung, Kabupaten Maros}

\section{Kependudukan}

Jumlah penduduk Kelurahan Kalabbirang adalah 3986 jiwa, jenis kelamin lakilaki sebanyak 1927 jiwa dan jenis kelamin perempuan sebanyak 2059 jiwa dengan jumlah kepala keluarga sebanyak 984 dan jumlah rumah sebanyak 1087 rumah. Mata

\footnotetext{
${ }^{1}$ https://id.wikipedia.org/wiki/Kalabbirang,_Bantimurung,_Maros
} 
pencaharian penduduk Kel. Kalabbirang sebagian besar adalah petani, pedagang, peternak, dan adapula warga yang berprofesi sebagai PNS.

\section{Pendidikan \& Keagamaan}

Pendidikan merupakan hal yang sangat penting dalam pembentukan pola piker dan pengembangan kualitas hidup masyarakat ${ }^{2}$, maka dari itu pendidikan harus ditunjang dengan ketersediaan sarana dan prasarana pendidikan yang layak dan bermutu agar fungsi dan tujuan pendidikan dapat tercapai dengan optimal ${ }^{3}$. Sarana pendidikan yang terdapat di Kelurahan Kalabbirang adalah: Taman Kanak-kanak 4 buah, Sekolah Dasar 4 buah, Sekolah Menengah Pertama 2 buah, Sekolah Menengah Atas 2 buah, dan Yayasan 1 buah. Adapun sarana peribadatan berguna untuk mengisi kebutuhan rohani masyarakat sesuai kepercayaan masing-masing. Penduduk Kelurahan Kalabbirang ratarata menganut agama Islam, hal ini terlihat dari sarana peribadatan berupa Masjid yang berjumlah 10 buah dan tidak terdapat rumah peribadatan yang lain.

\section{Kesehatan}

Upaya untuk meningkatkan pelayanan kesehatan masyarakat terus dilakukan oleh Pemerintah. Kesehatan sebagai salah satu hak dasar rakyat yang dilindungi undangundang saat ini terus dibangun dan ditingkatkan. Namun, untuk mencapai kualitas kesehatan masyarakat sebagaimana diharapkan bukanlah pekerjaan mudah karena besarnya tantangan yang harus dihadapi, terutama dalam menciptakan partisipasi seluruh lapisan masyarakat. ${ }^{4}$ Fasilitas kesehatan yang terdapat di Kelurahan Kalabbirang adalah Puskesmas berjumlah 1 unit, posyandu 1 unit dan rumah bersalin 1 unit.

Tujuan utama Puskesmas adalah untuk meningkatkan kesehatan dan mencegah penyakit dengan sasaran utamanya adalah masyarakat. ${ }^{5}$ Menurut Permenkes Nomor 75 Tahun 2014, Pusat Kesehatan Masyarakat yang selanjutnya disebut Puskesmas adalah fasilitas pelayanan kesehatan yang menyelenggarakan upaya kesehatan masyarakat dan upaya kesehatan perseorangan tingkat pertama, dengan lebih mengutamakan upaya promotif dan preventif, untuk mencapai derajat kesehatan masyarakat yang setinggitingginya di wilayah kerjanya.

Jika ditinjau dari sistem pelayanan kesehatan di Indonesia, maka peranan dan kedudukan Puskesmas adalah sebagai ujung tombak sistem pelayanan kesehatan di

\footnotetext{
${ }^{2}$ Dr. Meutia F. Swasono, staf pengajar di Departemen Antropologi FISIP UI, 2003

"Strategi Kebudayaan Nasional Indonesia: Penataan Pola Pikir", makalah diajukan pada Rakernas Persatuan Taman Siswa, 15-19 Februari 2004 di Jakarta. Hal 5.

${ }^{3}$ Krelisa. Kajian Prasarana Pendidikan Sekolah Dasar Sebagai Salah Satu Indikator Pencapaian Standar Nasional Pendidikan. Hal. 85

${ }^{4}$ Muh Ryman Napirah, Abd Rahman, Agustina Tony. Faktor-Faktor Yang Berhubungan Dengan Pemanfaatan Pelayanan Kesehatan Di Wilayah Kerja Puskesmas Tambarana Kecamatan Poso Pesisir Utara Kabupaten Poso

${ }^{5}$ Azwar, A. (2010). Pengantar administrasi kesehatan. Jakarta: Binarupa Aksara.
} 
WAHATUL MUJTAMA': Jurnal Pengabdian Masyarakat

Vol. 1, No. 2 (2020) : Hal. 157-173

Website: https://journal.stiba.ac.id

Indonesia. Hal ini disebabkan karena peranan dan kedudukan Puskesmas di Indonesia amat unik sebagai sarana pelayanan kesehatan primer yang bertanggung jawab dalam menyelenggarakan pelayanan kesehatan masyarakat sebagai upaya preventif. ${ }^{6}$

\section{PEMBAHASAN}

\section{A. Bentuk-Bentuk Kegiatan}

\section{Jumat Berkah}

Program jum'at berkah merupakan program sosial yang bertujuan untuk menumbuhkan jiwa sosial pada komunitas yang menjadi sasaran program ${ }^{7}$. Program ini dilaksanakan setiap hari Jumat sebagai bentuk peduli dan metode pendekatan mahasiswi kepada masyarakat sambil sebagai ajang membagikan undangan kegiatan selama KKN. Pertama-tama kami membeli kue di pasar dan kadang memesan untuk diambil Jumat pagi, kadang pula kami membeli bahan pada hari Kamis dan mulai membuatnya di malam hari, lalu pada pagi hari kami memasukkan kue tersebut ke dalam plastik mika yang sudah ditempelkan stiker bertuliskan "Jumat Berkah oleh Mahasiswi KKN STIBA Makassar”. Kemudian dibagikan ke warga yang kami temui di lokasi sasaran. Lokasi sasaran dibedakan setiap pekannya sehingga pembagian merata.

\begin{tabular}{ll}
\hline Nama Proker & Jumat Berkah \\
\hline Tujuan & $\begin{array}{l}\text { Mempererat hubungan silaturahim dengan warga melalui } \\
\text { program berbagi }\end{array}$ \\
\hline Kendala & $\begin{array}{l}\text { Bertepatan dengan hari pasar sehingga kadang ada } \\
\text { beberapa rumah yang kosong }\end{array}$ \\
\hline Solusi & $\begin{array}{l}\text { Bergerak lebih cepat agar bisa membagikan sebelum ibu- } \\
\text { ibu ke pasar }\end{array}$ \\
\hline Pengalaman & - Saat membagikan kue, masyarakat mengira kami \\
Menarik & $\begin{array}{l}\text { penjual atau peminta sumbangan } \\
\text { - Ada seorang ibu yang lumpuh dan jarang sekali warga } \\
\text { yang mengunjungi, maka beliau sangat terharu sampai } \\
\text { menitikkan air mata saat dikunjungi mahasiswi STIBA }\end{array}$
\end{tabular}

Faktor Pendukung Bertepatan dengan hari pasar sehingga memudahkan membeli kue yang akan dibagikan

\footnotetext{
${ }^{6}$ Muh. Ryman Napirah, Abd. Rahman, Agustina Tony. Faktor-Faktor Yang Berhubungan Dengan Pemanfaatan Pelayanan Kesehatan Di Wilayah Kerja Puskesmas Tambarana Kecamatan Poso Pesisir Utara Kabupaten Poso. Hal. 30. Jurnal Pengembangan Kota (2016) Volume 4 No. 1

${ }^{7}$ Lu'luin Fatihatul Baroroh. (2018). Menumbuhkan Jiwa Sosial Siswa Melalui Kegiatan Jum'at Berkah Di Sma Muhammadiyah Kediri (Skripsi, IAIN Kediri).
} 
WAHATUL MUJTAMA': Jurnal Pengabdian Masyarakat

Vol. 1, No. 2 (2020) : Hal. 157-173

Website: https://journal.stiba.ac.id

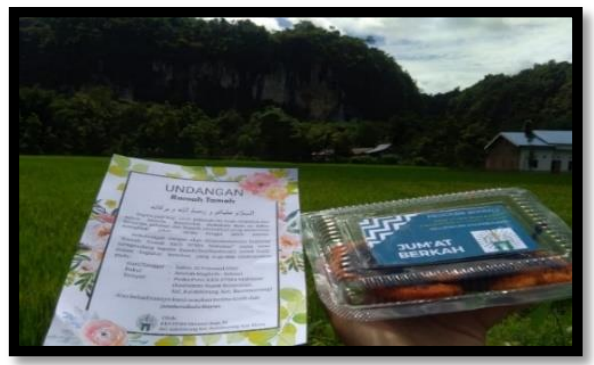

Gambar 1. Pembagian Jum'at Berkah kepada warga

Program ini dilaksanakan setiap hari Jumat sebagai bentuk peduli dan metode pendekatan mahasiswi kepada masyarakat sambil sebagai ajang membagikan undangan kegiatan selama KKN. Pertama-tama kami membeli kue di pasar dan kadang memesan untuk diambil Jumat pagi, kadang pula kami membeli bahan pada hari Kamis dan mulai membuatnya di malam hari, lalu pada pagi hari kami memasukkan kue tersebut ke dalam plastik mika yang sudah ditempelkan stiker bertuliskan "Jumat Berkah oleh Mahasiswi KKN STIBA Makassar”. Setelah itu dibagikan ke warga yang kami temui di lokasi sasaran. Lokasi sasaran dibedakan setiap pekannya sehingga pembagian merata.

\section{Taklim Fikih Muslimah}

Fikih merupakan ilmu yang sangat penting dipelajari. Secara umum program Taklim Muslimah memiliki kontribusi dalam meningkatkan pemahaman hak dan kedudukan wanita seperti, menambah dan meningkatkan kesadaran wanita muslimah tentang pentingnya mencari ilmu agama. ${ }^{8}$ Pada kegiatan taklim fiqih muslimah di desa Kalabbirang, diberikan batasan pada materi Bab Thaharah dan Shalat kepada ibu-ibu peserta taklim dengan harapan agar mereka memperbaiki tata cara bersuci dan shalat sesuai yang diajarkan Rasulullah Shallallaahu 'Alaihi wa Sallam. Awalnya kami hanya mengadakan di satu masjid, melihat antusias ibu-ibu mengikuti taklim ini, kami kemudian melebarkan hingga ke 3 masjid lainnya. Taklim dimulai dengan pembukaan majelis, tilawatul qur'an, lalu penyampaian materi, kemudian ada sesi tanya jawab. Kami juga menyediakan kue-kue dan air minum yang dikonsumsi di akhir acara.

\footnotetext{
${ }^{8}$ Riswana. (2018). Peranan Taklim Muslimah dalam Meningkatkan Pemahaman Hak dan Kedudukan Wanita dalam Rumah Tangga (Studi pada Yayasan Markaz Imam Malik Kota Makassar) (Skripsi, Universitas Islam Negeri Alauddin Makassar).
} 
WAHATUL MUJTAMA': Jurnal Pengabdian Masyarakat

Vol. 1, No. 2 (2020) : Hal. 157-173

Website: https://journal.stiba.ac.id

\begin{tabular}{ll}
\hline Nama Proker & Taklim Fikih Muslimah \\
\hline Tujuan & Menambah wawasan fikih \\
\hline Tempat & $\begin{array}{l}\text {-Masjid Nurul Mu'minin Kalabbirang } \\
\text {-Masjid Nurul Muttaqin Pakalu } \\
\text {-Masjid Nurul Jannah Tompobalang } \\
\text {-Masjid Nurul Hidayah Pakalu }\end{array}$ \\
\hline Kendala & $\begin{array}{l}\text { Tidak semua mahasiswi siap ketika ditunjuk sebagai } \\
\text { pemateri }\end{array}$ \\
\hline Solusi & $\begin{array}{l}\text { Mengadakan pelatihan daiyah sebelum pelaksanaan } \\
\text { KKN }\end{array}$ \\
\hline Pengalaman Menarik & $\begin{array}{l}\text { Ibu-ibu sangat antusias dan semangat sampai tidak } \\
\text { ingin berhenti padahal waktu sudah habis }\end{array}$ \\
\hline Faktor Pendukung & $\begin{array}{l}\text { Pemateri bisa berbicara dengan bahasa daerah yang } \\
\text { dipahami peserta sehingga menambah antusias } \\
\text { peserta }\end{array}$ \\
\hline
\end{tabular}

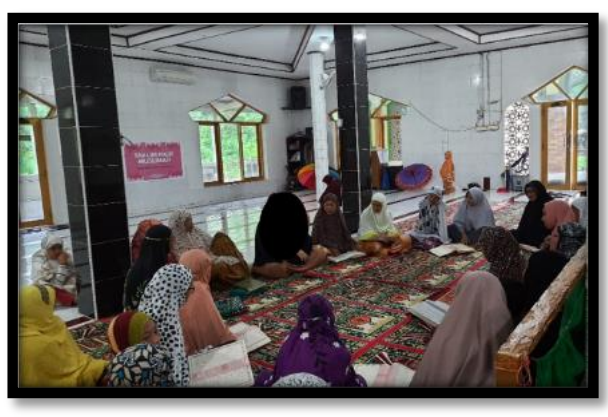

Gambar 2. Taklim Fikih Muslimah

\section{Pembinaan TPA}

Taman Pendidikan Al-Qur'an (TPA) merupakan salah satu lembaga yang memberikan layanan berupa pengetahuan dan keterampilan dalam menulis, membaca dan mengamalkan Al-Qur'an dalam kehidupan sehari-hari. ${ }^{9}$ TPA sebagai unit dasar dalam pengajaran dan pembelajaran Al Qur'an idealnya memiliki standar, mekanisme, dan evaluasi yang jelas agar pembelajaran Al-Qur'an dapat berjalan secara efektif dan evaluatif untuk melihat dan memperbaiki berbagai kekurangan, namun pada

\footnotetext{
${ }^{9}$ Dede Abdurrohman. (2017). Efektivitas Program Pembelajaran Taman Pendidikan Al-Qur'an (TPA) Dalam Meningkatkan Kemampuan Membaca Al-Qur'an di TPA Al-Hikmah Desa Sidosari Natar Lampung Selatan (Skripsi, UIN Raden Intan Lampung).
} 
WAHATUL MUJTAMA': Jurnal Pengabdian Masyarakat

Vol. 1, No. 2 (2020) : Hal. 157-173

Website: https://journal.stiba.ac.id

pelaksanaannya sistem pendidikan TPA di Indonesia sebagian besarnya belum mempunyai standar dan mekanisme tersebut. ${ }^{10}$

Kegiatan pengabdian masyarakat melalui program pembinaan TPA ini dimulai dengan pembukaan majelis, kemudian pembacaan surah plihan oleh seluruh santri TPA secara bersamaan, dan dilanjutkan dengan perbaikan bacaan. Setiap pengajar menyimak bacaan Al-Qur'an dari setiap santri sekaligus mengoreksi kesalahan tajwid. Kegiatan ini ditutup dengan penyetoran hafalan surah pilihan.

\begin{tabular}{lll}
\hline Nama Proker & Pembinaan TPA \\
\hline Tujuan & $\begin{array}{l}\text { Mengajarkan dan membimbing anak agar bisa membaca } \\
\text { Al-Qur'an dan menambah wawasan keislaman }\end{array}$ \\
\hline \multirow{2}{*}{ Realisasi } & Waktu & Senin-Jumat Pukul 15.00-17.00 \\
\cline { 2 - 3 } & $\begin{array}{l}\text { Tempat } \\
\text { Mengajar }\end{array}$ & $\begin{array}{l}\text {-TPA Al-Humairah Kalabbirang } \\
\text {-TPA Nurul Muttaqin Pakalu } \\
\text {-TPA Rabbani Bantimurung }\end{array}$ \\
\hline Kendala & $\begin{array}{l}\text { Keterlambatan sebagian mahasiswi datang ke tempat } \\
\text { TPA }\end{array}$ \\
\hline Solusi & Lebih mengatur waktu dengan baik \\
\hline Pengalaman Menarik & $\begin{array}{l}\text { Anak-anak sangat semangat ke TPA, mereka datang satu } \\
\text { jam lebih awal dari jadwal yang ditentukan }\end{array}$ \\
\hline Faktor Pendukung & Antusias yang tinggi dari para santri \\
\hline
\end{tabular}

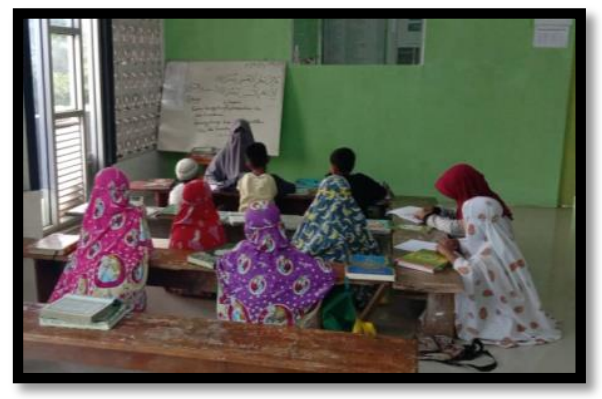

Gambar 3. Pembinaan TPA

\section{Program DIROSA}

DIROSA merupakan sebuah metode praktis pengajaran membaca Alquran yang diperuntukkan khusus kepada kaum remaja dan orang tua, program ini berjalan secara dinamis dan sistematis, dilaksanakan selama kurung waktu tertentu dengan materi yang

\footnotetext{
${ }^{10}$ Unggul Priyadi, Hidayat Nur Syarif, Aprilia Islamawati. (2013). Peningkatan Mutu Pembelajaran Taman Pendidikan Alquran Dengan Pembuatan Kurikulum TPA. Asian Journal of Innovation and Entrepreneurship, 2(03), 204-211.
} 
WAHATUL MUJTAMA': Jurnal Pengabdian Masyarakat

Vol. 1, No. 2 (2020) : Hal. 157-173

Website: https://journal.stiba.ac.id

berjenjang. ${ }^{11}$ Kegiatan ini dimulai dengan pembukaan majelis oleh pengajar, sekaligus pemberian motivasi agar peserta tetap antusias dalam belajar, kemudian kegiatan dilanjutkan dengan pembelajaran sesuai dengan buku panduan teknik mengajarkan DIROSA.

\begin{tabular}{ll}
\hline Nama Proker & Program DIROSA \\
\hline Tujuan & $\begin{array}{l}\text { Mengajarkan dan memperbaiki bacaan Al-Qur'an } \\
\text { untuk orang dewasa }\end{array}$ \\
\hline Kendala & Sempitnya waktu di malam hari \\
\hline Solusi & Mengadakan kembali DIROSA di waktu siang hari \\
\hline Pengalaman Menarik & $\begin{array}{l}\text {-Penyebutan huruf tanwin diucapkan dengan "NG" } \\
\text {-Diantarapeserta DIROSA ada yang berumur 72 tahun, } \\
\text { namun memiliki semangat yang tinggi dalam belajar } \\
\text { mengaji. }\end{array}$ \\
\hline Faktor Pendukung & $\begin{array}{l}\text { Metode DIROSA yang disukai oleh ibu-ibu karena } \\
\text { berbeda dengan metode pembelajaran yang lain, } \\
\text { menambah antusias ibu-ibu dalam menghadiri } \\
\text { DIROSA }\end{array}$ \\
\hline
\end{tabular}

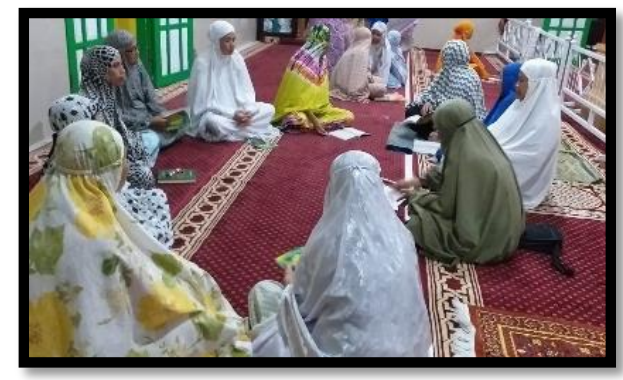

Gambar 4. Program Dirosa

\section{Program Tahsin}

Program tahsin merupakan rangkaian program pembelajaran Al Qur'an yang telah disebutkan sebelumnya. Program pembelajaran Al Quran menjadi program yang banyak menghiasi pengabdian masyarakat mahasiswi KKN karena pembelajaran Al-Qur'an dianggap sebagai sesuatu yang sangat mendasar sebagai sebuah kebutuhan dan kewajiban. Kegiatan tahsin dimulai dengan pembukaan majelis, lalu pengajar menjelaskan materi tahsin kemudian masing-masing peseta mempraktekkan.

\footnotetext{
${ }^{11}$ Muhammad Saddang, Abubakar, A., \& Munir, M. (2018). Implementasi Metode Dirosa Dalam Pembelajaran Al-Qur'an Dewan Pimpinan Daerah Wahdah Islamiyah Makassar. Jurnal Diskursus Islam, 6(3), 481-500.
} 
WAHATUL MUJTAMA': Jurnal Pengabdian Masyarakat

Vol. 1, No. 2 (2020) : Hal. 157-173

Website: https://journal.stiba.ac.id

\begin{tabular}{ll}
\hline Nama Proker & Program Tahsin \\
\hline Tujuan & Memperbaiki bacaan Al-Qur'an \\
\hline Sasaran & Muslimah Kel. Kalabbirang \\
\hline Kendala & Waktu sempit (ba'da maghrib) \\
\cline { 2 - 2 } & Peserta kekurangan buku pendamping \\
\hline Solusi & Membawa buku tahsin ke tempat KKN \\
\hline Pengalaman Menarik & $\begin{array}{l}\text { Peserta bertanya melalui chat bahkan mendatangi posko } \\
\text { KKN demi bertanya perihal makharijul huruf }\end{array}$ \\
\hline Faktor Pendukung & Semangat para peserta \\
\hline
\end{tabular}

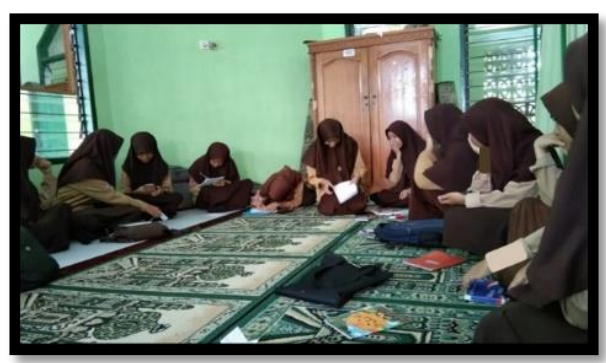

Gambar 6. Program Tahsin

\section{Tarbiyah Islamiyah}

Tarbiyah Islamiyah merupakan kegiatan pembelajaran dasar-dasar keislaman secara intensif dan berkesinambungan. Secara teknis kegiatan tarbiyah dilakukan melalui kelompok kecil yang disebut halaqah yang diawali dengan tadarrus atau perbaikan bacaan Al Qur'an sekaligus mengambil hikmah dengan mentadabburi ayat-ayat-Nya, kemudian memasuki materi tarbiyah yang disesuaikan dengan jenjang dan tingkat pemahaman peserta tarbiyah ${ }^{12}$.

Kegiatan ini dimulai dengan pembukaan majelis, kemudian tahsinul qiraah, setiap mutarabbiyah membaca Al-Qur'an secara bergiliran, lalu murabbiyah mengoreksi setiap bacaan yang salah dari mutarabbiyahnya. Sebelum melanjutkan materi maka terlebih dahulu mereview materi sebelumnya, juga ada sesi tanya jawab setelah materi.

\footnotetext{
${ }^{12}$ Nuzul Haq, \& Suryani Mursalim. (2016). Penerapan Tarbiyah Islamiyah dalam Pembinaan Akhlak Siswa Sekolah Menengah Pertama Islam Terpadu Wahdah Islamiyah Makassar. Jurnal Tomalebbi, (1), 63-68.
} 
WAHATUL MUJTAMA': Jurnal Pengabdian Masyarakat

Vol. 1, No. 2 (2020) : Hal. 157-173

Website: https://journal.stiba.ac.id

\begin{tabular}{ll}
\hline Nama Proker & Tarbiyah Islamiyah \\
\hline Tujuan & Mencetak generasi mukmin \\
\hline Sasaran & Muslimah Kel. Kalabbirang \\
\hline Kendala & Kehadiran peserta kurang maksimal \\
\hline Solusi & $\begin{array}{l}\text { Memotivasi peserta tentang pentingnya mendatangi } \\
\text { majelis ilmu }\end{array}$ \\
\hline Pengalaman Menarik & $\begin{array}{l}\text { Pernah diingatkan oleh petugas penjaga ruangan di } \\
\text { sekolah karena lupa waktu untuk berhenti pada saat } \\
\text { mengisi halaqoh. }\end{array}$ \\
\hline Faktor Pendukung & $\begin{array}{l}\text { Para mutarabbiyah sangat antusias dalam mempelajari } \\
\text { agama islam. }\end{array}$ \\
\hline
\end{tabular}

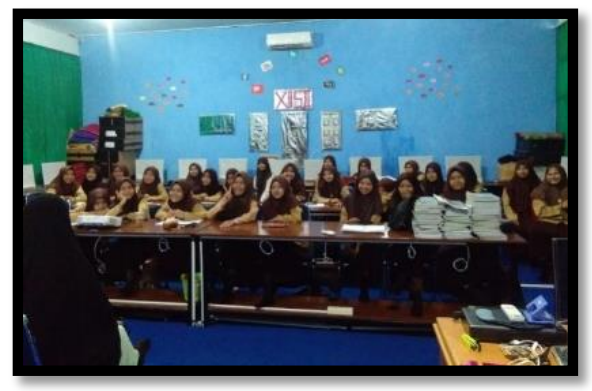

Gambar 7. Tarbiyah Islamiyah

\section{Halaqah Lughawiyah}

Program ini dilaksanakan dengan mengajarkan bahasa Arab kepada anakanak TPA, SD, dan SMA dengan tujuan memperkenalkan dan menumbuhkan kecintaan pada bahasa Arab, caranya dengan memberikan mufrodat-mufrodat dan dasar-dasar bahasa Arab.

\begin{tabular}{ll}
\hline Nama Proker & Halaqah Lughawiyah \\
\hline Tujuan & Menambah pengetahuan Bahasa Arab \\
\hline Sasaran & Siswa(i) SD-SMA \\
\hline Kendala & Kurangnya muqorror \\
\hline Solusi & Mempersiapkan muqorror untuk dibawa ke tempat \\
& KKN \\
\hline Pengalaman Menarik & Bermain tebak kata dengan peserta \\
\hline Faktor Pendukung & Peserta semangat dan antusias belajar Bahasa Arab \\
\hline
\end{tabular}




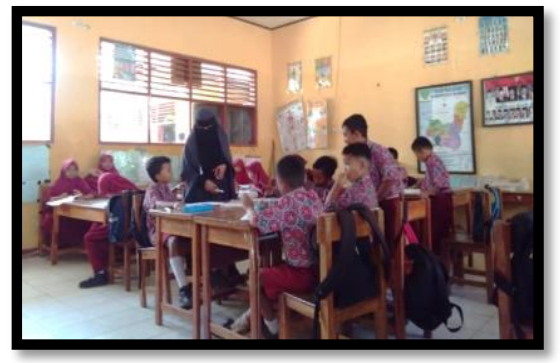

\section{Taklim Remaja}

\section{Gambar 8. Halaqah Lughawiyah}

Generasi muda saat ini menjadi sasaran berbagai program dekadensi akhlak dan moral terlebih lagi di zaman keterbukaan dan kemudahan teknologi seperti saat ini, oleh karena itu dibutuhkan upaya yang serius dan kontributif dalam menjaga generasi muda saat ini diantarnya melalui pembinaan intensif remaja (taklim) ${ }^{13}$. Program ini kami lakukan dengan mengajak siswi yang telah mengikuti halaqah tarbiyah dan lughawiyah untuk menghadiri taklim remaja sekaligus mengarahkan untuk mengajak teman-teman mereka. Kami juga menyebarkan pamflet secara langsung maupun melalui media sosial. Pada pelaksanannya, acara dibuka oleh MC lalu dilanjutkan dengan tilawatul qur'an dan pemaparan materi, juga dilengkapi dengan slide dan video menarik yang sesuai dengan tema taklim. Kami juga menyelipkan video sosialisasi Kampus STIBA Makassar sebagai perkenalan, terutama bagi mahasiswi kelas XII yang akan melanjutkan pendidikan ke perkuliahan.

\begin{tabular}{lll}
\hline Nama Proker & Taklim Remaja \\
\hline Tujuan & Menambah wawasan keislaman para remaja \\
\hline Sasaran & Pemudi Kel. Kalabbirang \\
\hline Realisasi & Peserta & TR I : 52 orang $\quad$ TR II : 60 orang \\
\cline { 2 - 3 } & Waktu & 24 Januari dan 7 Februari 2020 Pukul 11.30-13.00 \\
\cline { 2 - 3 } & Tempat & SMAN 4 Bantimurung-Maros \\
\hline Kendala & Pada TR pertama, sound system kurang memadai \\
\hline Solusi & $\begin{array}{l}\text { Mencari alternatif lain dengan meminjam sound system } \\
\text { milik kantor sekolah }\end{array}$ \\
\hline Pengalaman Menarik & $\begin{array}{l}\text { Peserta lebih terbuka kepada pemateri sehingga diantara } \\
\text { peserta memilih curhat mengenai masalah pribadinya. }\end{array}$ \\
\hline Faktor Pendukung & $\begin{array}{l}\text { Antusias dari peserta yang cukup tinggi, dan pihak } \\
\text { sekolah sangat mendukung kegiatan ini. }\end{array}$ \\
\hline
\end{tabular}

\footnotetext{
${ }^{13}$ Saputro, Y. E., Mansur, R., \& Mustafida, F. (2019). Peranan Majelis Taklim Waqiah Indonesia Dalam Pembinaan Akhlak Remaja Di Perumahan Joyogrand Merjosari Malang. Vicratina: Jurnal Pendidikan Islam, 4(7), 71-75.
} 


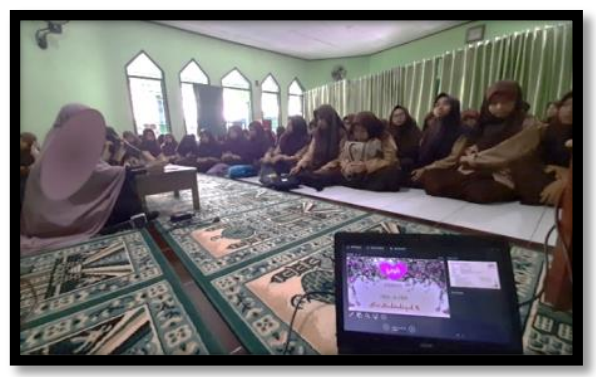

Gambar 9. Taklim Remaja

\section{Tadabbur Alam}

Tadabbur alam adalah upaya untuk meningkatkan kesadaran naturalis dan kesadaran spiritual pada diri manusia ${ }^{14}$. Program ini dikemas melalui berbagai kegiatan di alam terbuka yang menyegarkan dan menyenangkan, namun tetap memperhatikan substansi perenungan atas kekuasaan Allah azza wa jalla, yang Maha Pencipta. Program tadabbur alam dilaksanakan dengan terlebih dahulu menginformasikan kepada anakanak untuk berkumpul di posko atau masjid, lalu kami mencatat jumlah anak yang akan ikut kegiatan ini. Kemudian kami membawa mereka ke tempat tadabbur alam, sambil jalan kami memberikan pengetahuan bahasa Arab tentang benda-benda yang dilihat dan menjelaskan tentang kekuasaan Allah dalam menciptakan alam. Lalu kami bermain bersama dan makan kemudian pulang.

\begin{tabular}{ll}
\hline Nama Proker & Tadabbur Alam \\
\hline Tujuan & $\begin{array}{l}\text { Menanamkan kecintaan kepada Allah melalui } \\
\text { pengenalan lingkungan sekitar }\end{array}$ \\
\hline Waktu dan Tempat & TA 1 : 19 Januari 2020 di Leang Lompoa \\
& TA 2 : 25 Januari 2020 di Agro Wisata \\
& TA 3 : 19 Februari 2020 di Permandian Uluwae \\
& TA 4 : 23 Februari 2020 di Taman Wisata Leang-Leang \\
\hline Kendala & Anak-anak kadang susah diatur, perlu suara besar \\
& untuk mengarahkan mereka. \\
\hline Solusi & Memaksimalkan kinerja panitia \\
\end{tabular}

\footnotetext{
${ }^{14}$ Hilmi Hambali. (2017). Eksplorasi Pembelajaran Tadabbur Alam Dalam Meningkatkan Kecerdasan Naturalis (Naturalistik Intellegence) Dan Kecerdasan Spiritual (Spiritual Intellegence) Siswa SMP Unismuh Makassar. Jurnal Pendidikan Fisika, 5(1), 99-108.
} 
WAHATUL MUJTAMA': Jurnal Pengabdian Masyarakat

Vol. 1, No. 2 (2020) : Hal. 157-173

Website: https://journal.stiba.ac.id

\begin{tabular}{ll}
\hline Pengalaman Menarik & Anak-anak sangat bersemangat sampai-sampai mereka \\
& datang lebih awal dari waktu berkumpul yang \\
& ditentukan dan dengan persiapan yang lengkap tanpa \\
& diarahkan. Sangat antusias dalam menanyakan bahasa \\
& Arab dari benda yang ditemui di tempat kegiatan, \\
& mereka baru menyadari kekuasaan Allah dalam \\
& menciptakan alam dan isinya dengan ekspresi kagum \\
dan bersyukur.
\end{tabular}

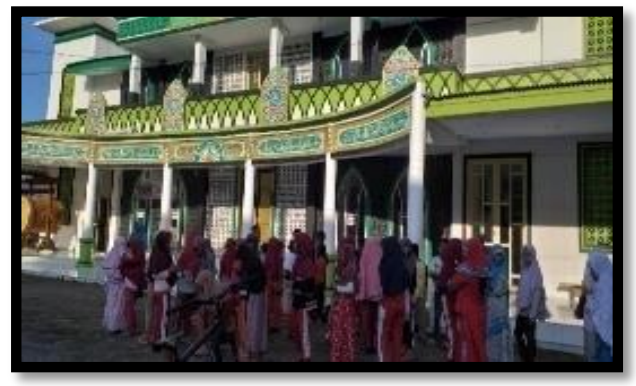

Gambar 10. Tadabbur Alam

\section{Pelatihan Kerajinan Tangan}

Diawali dengan pengenalan bahan dan langkah-langkah dasar, selanjutnya dipraktekkan satu persatu, sebagian besar dari peserta cepat menguasai sehingga dalam satu kali pertemuan sudah menguasai $70 \%$ dari apa yang mau diberikan.

\begin{tabular}{|c|c|c|}
\hline Nama Proke & & Pelatihan Kerajinan Tangan \\
\hline Tujuan & & Menambah keterampilan muslimah di Kalabbirang \\
\hline \multirow{3}{*}{ Realisasi } & Peserta & 10 orang \\
\hline & Waktu & Sabtu, 1 Februari 2020 Pukul 16.00-17.30 \\
\hline & Tempat & Posko KKN Mahasiswi STIBA Makassar \\
\hline Kendala & & $\begin{array}{l}\text { Kurangnya komunikasi antara PJ dan peserta } \\
\text { mengenai ketetapan waktu }\end{array}$ \\
\hline Solusi & & $\begin{array}{l}\text { Memperbaiki dan memperjelas komunikasi antara } \\
\text { PJ dan peserta }\end{array}$ \\
\hline \multicolumn{2}{|c|}{ Pengalaman Menarik } & $\begin{array}{l}\text { Pertama kali melatih nenek-nenek, semangatnya } \\
\text { luar biasa meskipun tak kunjung bisa }\end{array}$ \\
\hline
\end{tabular}




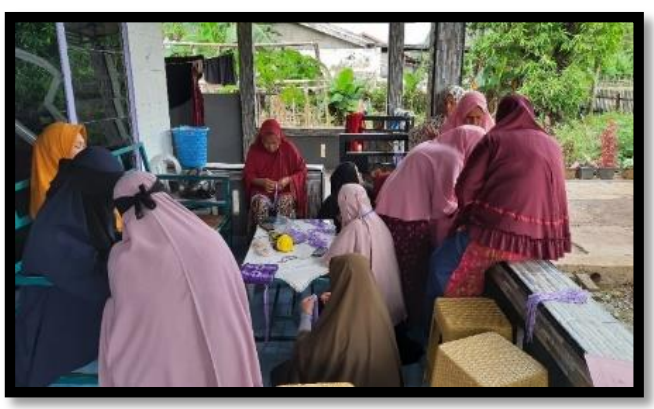

Gambar 11. Pelatihan Kerajinan Tangan

\section{Pelatihan Penyelenggaraan Jenazah}

Pertama-tama kami menargetkan lokasi yang strategis dan berkoordinasi dengan Muslimah Wahdah Maros perihal kapan akan dilaksanakan. Kegiatan ini dirangkaikan dengan Tabligh Akbar agar lebih menarik banyak peserta untuk hadir. Sebelum hari kegiatan, semua alat dan bahan PPJ sudah dipersiapkan terutama kain kafan.

\begin{tabular}{lll}
\hline Nama Proker & Pelatihan Penyelenggaraan Jenazah \\
\hline Tujuan & $\begin{array}{l}\text { Memberikan pengetahuan penyelenggaran jenazah } \\
\text { sesuai syariat }\end{array}$ \\
\hline Realisasi & Peserta & Laki-laki : 10 orang Perempuan : 23 orang \\
\cline { 2 - 3 } & Waktu & Sabtu, 1 Februari 2020 Pukul 08.00-12.00 \\
\cline { 2 - 3 } & Tempat & Masjid Nurul Muttaqin Pakalu \\
Kendala & $\begin{array}{l}\text { Hujan deras yang mengakibatkan kurangnya peserta } \\
\text { yang hadir }\end{array}$ \\
\hline Solusi & $\begin{array}{l}\text { Lebih memaksimalkan sosialisasi ke masyarakat } \\
\text { secara langsung }\end{array}$ \\
\hline Pengalaman Menarik & Akhwat secara langsung berperan sebagai jenazah \\
\hline Faktor Pendukung & $\begin{array}{l}\text { Peserta dilibatkan secara langsung dalam } \\
\text { menggunting kain kafan, hal ini membuat peserta } \\
\text { lebih fokus }\end{array}$
\end{tabular}

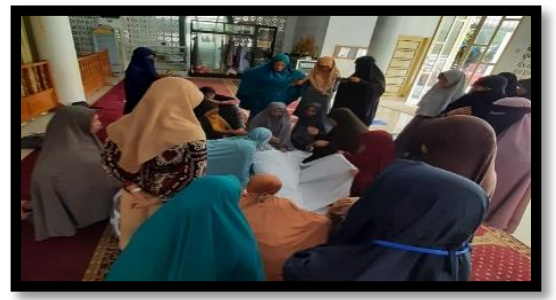

Gambar 12. Pelatihan Penyelenggaraan Jenazah 
WAHATUL MUJTAMA': Jurnal Pengabdian Masyarakat

Vol. 1, No. 2 (2020) : Hal. 157-173

Website: https://journal.stiba.ac.id

\section{Festival Anak Saleh}

Festival ini berlangsung selama 6 hari untuk menyeleksi peserta yang berhak mewakili kelurahan ditingkat kecamatan. Adapun jenis lomba pada kegiatan ini terdiri dari 6 cabang lomba yaitu: lomba adzan, MHQ, MTQ, Pildacil, CCI, dan rangking satu. Setiap hari selama sepekan diadakan seleksi untuk 1 cabang lomba. Hari Senin : lomba adzan, Selasa : lomba pildacil, Rabu : lomba MTQ, Kamis : lomba CCI, Jumat: lomba MHQ, dan Sabtu : lomba rangking satu. Kegiatan ini ditutup dengan penerimaaan hadiah yang dirangkaikan dengan tablig akbar.

\begin{tabular}{lll}
\hline Nama Proker & Festival Santri Tingkat Kelurahan \\
\hline Tujuan & & Menguji wawasan keislaman anak-anak \\
\hline Realisasi & Peserta & (data terlampir) \\
\cline { 2 - 3 } & Waktu & Senin-Sabtu, 3-8 Februari 2020 Pukul 16.00-17.45 \\
\cline { 2 - 3 } & Tempat & $\begin{array}{l}\text { Masjid Nurul Mu'minin Kalabbirang dan Halaman } \\
\text { SDN 121 Inp. Kalabbirang }\end{array}$ \\
\hline Kendala & $\begin{array}{l}\text { Adanya kesulitan dalam mengatur anak-anak yang } \\
\text { hadir pada saat acara berlangsung }\end{array}$ \\
\hline Solusi & $\begin{array}{l}\text { Memaksimalkan kerja panitia dalam mengatur peserta } \\
\text { dan penonton pada saat acara berlangsung }\end{array}$
\end{tabular}

Pengalaman Menarik Ada diantara peserta yang menagis karena tidak bisa menjawab soal lomba

$\begin{array}{ll}\text { Faktor Pendukung } & \text { Acara ini diadakan sore hari, sehingga para peserta } \\ \text { lomba dapat memaksimalkan kehadiran pada saat } \\ \text { lomba }\end{array}$

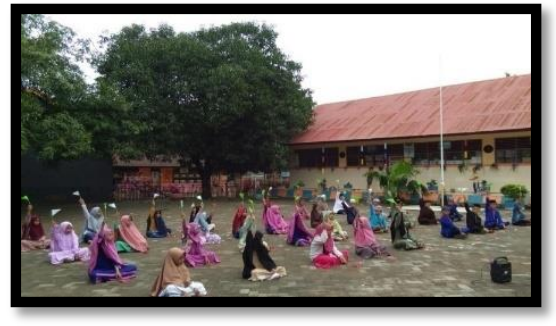

Gambar 13. Festival Anak Soleh

Para mahasiswi dalam menyelesaikan 18 program kerjanya perlu melakukan follow up pada beberapa program kerja agar program kerja tersebut dapat memberikan manfaat bagi masyarakat serta dakwah yang sudah dirintis selama sebulan lebih dalam masa KKN yang mulai diterima oleh masyarakat tetap berlanjut. Ini adalah bagian dari 
tanggung jawab dakwah yang harus menjadi prioritas. Diantara program yang dipandang perlu untuk ditindaklanjuti adalah, DIROSA, halaqah lughawiyah, taklim fikih muslimah; Tahsin; dan tarbiyah.

\section{KESIMPULAN}

Berdasarkan uraian program kerja dan pelaksanaan Program Kerja Mahasiswa Sekolah Tinggi Ilmu Islam dan Bahasa Arab (STIBA) tahun akademik 2019/2020 di Kel. Kalabbirang, Kec. Bantimurung, Kab. Maros, maka dapat disimpulkan bahwa pelaksanaan KKN Mahasiswi STIBA Makassar di Kelurahan Kalabbirang, Kecamatan Bantimurung, Kecamatan Maros berjalan dengan baik. Program kerja yang telah disukseskan berjumlah 13 program kerja dan 5 program kerja diantaranya membutuhkan follow up yaitu DIROSA, tarbiyah, tahsin, halaqah lughawiyyah dan taklim fikih muslimah. KKN telah berhasil membentuk para mahasiswa/i dalam hal: 1) Pengalaman belajar dan bekerja dalam melaksanakan kegiatan pengabdian kepada masyarakat secara langsung yang akhirnya memberikan sifat profesionalisme pada diri mahasiswi; 2) Memiliki keterampilan dalam merencanakan, merumuskan serta melaksanakan programprogram kerja; 3) Memiliki keterampilan dalam memecahkan masalah yang terjadi dalam masyarakat secara langsung; 4) Memahami adanya hubungan ketergantungan dan keterkaitan kerjasama antara anggota dalam mengelola program kerja; 5) Memiliki rasa kepedulian sosial yang tinggi; 6) Mampu memberikan sumbangsih kepada masyarakat dalam bentuk riset yang terwujudkan dalam karya ilmiah.

\section{DAFTAR PUSTAKA}

Abdurrohman, D. (2017). Efektivitas Program Pembelajaran Taman Pendidikan AlQur'an (TPA) Dalam Meningkatkan Kemampuan Membaca Al-Qur'an di TPA AlHikmah Desa Sidosari Natar Lampung Selatan (Doctoral dissertation, UIN Raden Intan Lampung).

Hambali, H. (2017). Eksplorasi Pembelajaran Tadabbur Alam Dalam Meningkatkan Kecerdasan Naturalis (Naturalistik Intellegence) Dan Kecerdasan Spiritual (Spiritual Intellegence) Siswa SMP Unismuh Makassar. Jurnal Pendidikan Fisika, 5(1), 99-108.

Haq, N., \& Mursalim, S. (2016). Penerapan Tarbiyah Islamiyah dalam Pembinaan Akhlak Siswa Sekolah Menengah Pertama Islam Terpadu Wahdah Islamiyah Makassar. Jurnal Tomalebbi, (1), 63-68.

Napirah, M. R., Rahman, A., \& Tony, A. (2016). Faktor-faktor yang berhubungan dengan pemanfaatan pelayanan kesehatan di wilayah kerja Puskesmas Tambarana 
WAHATUL MUJTAMA': Jurnal Pengabdian Masyarakat

Vol. 1, No. 2 (2020) : Hal. 157-173

Website: https://journal.stiba.ac.id

Kecamatan Poso Pesisir Utara Kabupaten Poso. Jurnal Pengembangan Kota, 4(1), 29-39.

Relisa, R. (2016). Kajian Prasarana Pendidikan Sekolah Dasar Sebagai Salah Satu Indikator Pencapaian Standar Nasional Pendidikan. Jurnal Pendidikan dan Kebudayaan, Vol.1, No.1. Hal. 81-95

Riswana, R. (2018). Peranan Taklim Muslimah dalam Meningkatkan Pemahaman Hak dan Kedudukan Wanita dalam Rumah Tangga (Studi pada Yayasan Markaz Imam Malik Kota Makassar) (Skripsi, Universitas Islam Negeri Alauddin Makassar).

Saputro, Y. E., Mansur, R., \& Mustafida, F. (2019). Peranan Majelis Taklim Waqiah Indonesia Dalam Pembinaan Akhlak Remaja Di Perumahan Joyogrand Merjosari Malang. Vicratina: Jurnal Pendidikan Islam, 4(7), 71-75.

Swasono, M. F. H. (2003). Kebudayaan Nasional Indonesia: Penataan Pola Pikir. Makalah disampaikan dalam Kongres Kebudayaan, 501.

Saddang, M., Achmad Abubakar, Munir. (2018). Implementasi Metode Dirosa Dalam Pembelajaran Al-Qur'an Dewan Pimpinan Daerah Wahdah Islamiyah Makassar. Jurnal Diskursus Islam, 6(3), 481-500.

Priyadi,U., Syarif, H.N., Islamawati, A. (2013). Peningkatan Mutu Pembelajaran Taman Pendidikan Alquran Dengan Pembuatan Kurikulum TPA. Asian Journal of Innovation and Entrepreneurship, 2(03), 204-211.

Kalabbirang, Bantimurung, $\quad$ (2020, Saros. https://id.wikipedia.org/wiki/Kalabbirang,_Bantimurung,_Maros 